\title{
Financial Product Choices: Does Attribute Preference Help Avoid the Attraction Effect?
}

\author{
Viera Bačová, Róbert Hanák \\ Institute of Experimental Psychology, Centre for Social and Psychological Sciences, \\ Slovak Academy of Sciences
}

\begin{abstract}
The attraction effect occurs when a third option is added to two seemingly equivalent options but it competes against only one of the original options. This increases the likelihood of the dominating option being chosen. In attraction effect studies, it is assumed that both attributes of the options are of equal importance to the decision maker. We aimed to examine whether attribute preference would affect the occurrence of the attraction effect when choosing financial products. A total of 487 undergraduate students were randomly assigned to groups with the financial product choice of two or three options. We found that when participants had no clear attribute preference the attraction effect occurred more frequently. Those with a clear preference for one attribute succumbed to the effect only when choosing a product unfamiliar to them. The research sheds light on two conditions of the attraction effect: the product familiarity and the attribute preference.
\end{abstract}

Key words: attraction effect; financial product choices; attribute importance

\section{The Attraction Effect}

Making a decision involves having to choose between two or more items or products. As these possess different attributes (for example a higher price or a higher quality),

\footnotetext{
Acknowledgment

This research was supported by a grant from Slovak Ministry of Education, Science, Research and Sport of the Slovak Republic VEGA 2/0118/17 Risk assessment in decision making of individuals on the personal and company/business finances and business opportunities.
}

Correspondence concerning this article should be addressed to Prof. Viera Bačová, Institute of Experimental Psychology, Centre for Social and Psychological Sciences, Slovak Academy of Sciences, Dúbravská cesta 9, 84104 Bratislava, Slovak Republic. E-mail: viera.bacova@savba.sk

Received March 14, 2018 varying in importance to the decision maker, identifying which is most attractive is often difficult. When one item does better on one attribute and the other on another attribute, and if the decision maker considers both attributes equally important, a trade-off is required, which is not easily achieved. Therefore the decision maker looks for ways to simplify the decision and reduce the effort required (Payne, Bettman, \& Johnson, 1993). One way is to use the context provided by the set of options (Tversky \& Simonson, 1993).

One of the context effects to have gained most attention among decision theorists is the attraction effect (Huber, Payne, \& Puto, 1982). It occurs when a third option is added to two seemingly equivalent options but it competes against only one of the original options, considerably increasing the likelihood of the dominating option being chosen. Numerous experimental studies have confirmed the robustness of the attraction effect in various experimental 
designs and in a wide range of domains and products (Dhar \& Simonson 2003; Mishra, Umesh, \& Stem, 1993; Simonson \& Tversky 1992; Sivakumar \& Cherian 1995; Wedell \& Petibone, 1996). Although the robustness of the attraction effect has recently been disputed (Frederick, Lee, \& Baskinet, 2014; Huber, Payne, \& Puto, 2014; Simonson, 2014; Yang \& Lynn, 2014), new experimental evidence and review studies have emerged emphasizing that "caution needs to be exercised before discounting the attraction effect's practical relevance" (Lichters, Sarstedt, \& Vogt, 2015, p. 3).

For the attraction effect to occur, the newly added option (also labelled the "decoy" or "irrelevant option") has to resemble the option we wish to make more favorable (also labelled the "target"). The decoy does less well on one of the attributes but not the other. The option the decoy makes less favorable on a particular aspect is called the "competitor" (Hedgcock \& Rao, 2009; Huber et al., 1982; Simonson, 1989; Simonson \& Tversky, 1992). The decoy is only minimally preferable, but sets up a relationship of dominance between the two original options (therefore the attraction effect is also known as the asymmetric dominance effect; Ariely \& Wallsten, 1995).

\section{Conditions Affecting the Attraction Effect and Attribute Importance}

Several research studies have sought to identify the conditions under which the attraction effect occurs and its intensity. The literature contains mixed findings on the role of conditions which attenuate or amplify the attraction effect. Malkoc, Hedgcock, and Hoeffler (2013) have summarized some of the factors that moderate (amplify or diminish) the attraction effect. They suggested that the attraction effect may be enhanced by, for example, the need to justify one's choice, higher product quality (options), product similarity, depletion, and decoy popu- larity. Attenuating factors may include meaningfulness, product familiarity, category knowledge, involvement, and preference strength. Nonetheless, there are some conditions which are clearly thought to influence the attraction effect but have yet to be investigated in relation to it.

In most attraction effect studies, it is assumed that the two original options are equivalents as they are chosen approximately equally often. At the same time, it is assumed that both attributes are of equal weight (importance) to the decision maker. But what if the decision maker considers one attribute to be more important than the other? Thus far in attraction effect research, the importance of the attributes to the decision maker has attracted little attention. Studies that have addressed this issue have produced contradictory conclusions.

In Malaviya and Sivakumar's experiments (1998), the attraction effect was more evident in participants who considered one of the attributes more important than in those who considered both attributes to be equally important. According to Malaviya and Sivakumar (1998), if one attribute is more important it makes it more difficult for decision makers to choose because they have to consider both the weight and local value of the attributes. Therefore instead of thinking hard, the decision maker is more likely to be influenced by the relationship between the decoy and the target option. The choice is easier for those who consider both attributes equally important, as they consider only the total value of the options. By contrast, Simonson (1989) considers the opposite case to be more valid. The attraction effect is more likely to occur if the attributes are equally important to the decision maker. This is because the choice becomes more complex and so the decision maker is more prone to rely on heuristics and the local dominance of the target option. In their study, Wedell and Pettibone (1996) concluded 
that the dominance of the target can be increased when the more important attribute dominates in the decoy, since this then reinforces the perception that the target option has a higher total value. The option that does better on a more important attribute will be preferred and ultimately chosen as decision makers can use the local dominance of the option to make their choice.

\section{Financial Products and the Attraction Effect}

Financial products have some specific characteristics that set them apart from the products typically investigated in relation to decision heuristics and biases.

On one hand, there are reasons why the attraction effect can be expected in the financial domain. Firstly, it is not possible to describe financial products without using realistic numerical attributes relevant to their use in the real environment. Expressing stimuli numerically (as opposed to using verbal descriptions and images) has been found to enhance the attraction effect (Frederick et al., 2014; Simonson, 2014). Secondly, the sophistication of financial products makes calculating the best option highly demanding, and math and financial skills and sometimes expertise are required, therefore, we may expect the use of heuristics including the attraction effect.

On the other hand, there are reasons why we should not expect the attraction effect in the financial domain. Firstly, given the importance of financial decisions, we can suppose that the decision maker is highly engaged and more vigilant when choosing financial products. In relation to non-financial products, Mishra et al. (1993) have observed that a high degree of engagement reduces the attraction effect. Another reason for not having the attraction effect is that in financial decisions the choice is often between undesirable options only; that is, all options may require expenditure. "When a choice is made from a set of undesirable options, a more vigilance-oriented mind-set is evoked, leading to the elimination of the otherwise robust attraction effect." (Malkoc et al., 2013, p. 318).

With these specific properties that act for and against the attraction effect, it is very difficult to determine which conditions will lead to the attraction effect occurring in financial product decision making.

Several researchers have investigated the attraction effect in financial product decisions (e.g., Herne, 1999 - monetary gambles; Schwarzkopf, 2003 - investment; Zhumakadyr uulu \& König, 2014 - loans). Yet many issues in this domain have yet to be resolved. Perhaps the main question to consider first is whether, when making a financial choice, the decision maker does all the necessary calculations to determine which option is most beneficial. The complexity of some financial products makes choosing difficult, as rationally calculating the optimal option requires the decision maker to have a certain cognitive capacity and willingness to make the effort. At least two scenarios are possible in this situation. In the first scenario, the decision maker is not willing to spend the time and effort on a tiring financial task and this enhances the likelihood of the attraction effect occurring (Pocheptsova, Amir, Dhar, \& Baumeister, 2009). In the second scenario, the decision maker may engage the cognitive processes to a greater extent, and this eliminates the attraction effect. We are inclined to believe that because people rarely follow the rules of rational decision making in general, attraction effect heuristics are also used to decide financial issues and this tendency is boosted when the person has to make a decision concerning a less well-known and more complex financial product. In this study our aim is to fill a gap in the literature by examining the role of attribute importance in financial product choices. 


\section{The Research}

Our aim was to investigate the attraction effect in decisions where participants have to choose between options involving financial products. We looked specifically at how much people care about the attributes of the options and how this affects the attraction effect both when choosing a more familiar financial product and a less familiar one. Our hypotheses inquires whether the subjective weighting of attributes can be used as a clue in making complicated financial choices.

If one of the attributes has greater subjective importance, this gives the decision maker an easy-to-use instruction manual for choosing the option that does best on the preferred attribute. Hence we formulated our first hypothesis as:

H1. Participants who regard one of the attributes of a financial product as more important are less prone to yield to the attraction effect as they choose the option that does best on the more important attribute, regardless of the decoy.

Participants who consider both attributes of a financial product to be equally important have to choose between two relatively equal options. Since making a trade-off is demanding, these participants will be prone to reduce task complexity and use heuristics, in this case the attraction effect. As they do not have a clear preference for some of the options, it will be possible to observe the attraction effect in their choices:

H2. Participants who regard both attributes of a financial product to be equally important are more prone to yield to the attraction effect as the decoy influences their choice.

We specified Hypothesis 3 as follows:

H3. Participants who regard both attributes of a financial product to be equally important yield to the attraction effect more when choosing less familiar financial products compared to choosing more familiar products.

\section{Method}

\section{Participants}

A total of 487 undergraduate students at Slovak universities completed the experiment without financial incentive. Participants were asked by their lecturers if they would be willing to answer some questions and make a few financial decisions for extra credit points.

Undergraduates were selected for several reasons. Given the characteristics of the financial products, we needed a sample that was cognitively capable of understanding what was expected, and able to compare the options and make the choice with some cognitive effort. The second reason for using university students was that we wanted to test the effects of familiarity and engagement with financial products. Some financial products (such as risky stock investment) remain unknown to students in early adulthood, but they understand the nature of the decision-making task.

The age of the participants ranged from 18 to 26 years old $(M=21.65, S D=2.49)$. Women accounted for $72 \%$ of the sample. We performed a power calculation before data collection. The a priori $\mathrm{G}$ power calculation for Chi-square test, comparing two groups, with expected medium effect size $(\mathrm{w}=0.3, \alpha$ error probability $=.05)$, produced a sample size of 145 respondents.

Of the 487 students, 206 (42.3\%) were studying management or economics, $168(34.5 \%)$ social science and $113(23.2 \%)$ natural or technical science.

\section{Design and Materials}

In the experiment the participants were randomly assigned to one of three between-subject conditions. They then indicated their choices in the financial decision tasks. The control group $(N=163)$ had only two options in the 
decision tasks (A, B), Experimental Group 1 $(N=188)$ had three options $(\mathrm{A}, \mathrm{B}, \mathrm{Ca})$ and $\mathrm{Ex}-$ perimental Group $2(N=136)$ had three options (A, B, Cb). The options were not randomized in the groups. Respondents were assigned to the groups randomly by MS Excel random number generator.

Six different products were presented in the financial decision tasks and participants were asked to choose one option in each of the six tasks. The products, which we assumed the participants would be more familiar with, were Mobile Rate, Current Account, and Savings Account; the expected less familiar products were Loan, Car Accident Insurance, and Investment. Each option was described using the two attributes most widely promoted in "real" world financial marketing. The descriptions of all the financial products and the attribute values used in the decision tasks are given in Table 1 in the Appendix. The control group's options differed in that one option (A) did better on Attribute 1, and the second option (B) did better on Attribute 2 (core set of options). The financial values of the attributes were calculated before the stimuli materials were created as we wished to produce two de facto equal options (A and B) comparable in values with none being evidently inferior to the other. For example, the difference in the financial value of Option A and Option B in the Loan task is only a few percentage points (3.4\%). Therefore, the stimuli material allowed respondents to make their decisions according to their preferences rather than being "pushed" into choosing the evidently financially better option of the two, especially where the second one had an evidently inferior financial value. This principle that the options should be comparable or equal in total values has been an essential part of the attraction effect stimuli.

In the experimental conditions, we created the third option, the decoys ( $\mathrm{Ca}$ and $\mathrm{Cb}$ ), using the same strategy for both attributes: we increased the frequency of the superior attribute of the target, by narrowing the difference in attribute where the target was more advantageous than the competitor. In Experimental Group 1 with the three options $\mathrm{A}, \mathrm{B}$, and $\mathrm{Ca}$, the third option was a decoy $(\mathrm{Ca})$, which had one inferior attribute compared to the target option (A). It was expected that this manipulation would encourage participants to choose option A. Similarly, in Experimental Group 2, the participants were presented with the three options $\mathrm{A}, \mathrm{B}$, and $\mathrm{Cb}$, where the decoy $(\mathrm{Cb})$ had one inferior attribute compared to target option B. It was expected that this manipulation would encourage participants to choose option B. An example of the decoys created for the Loan financial product for both experimental groups is given in Figures $1 \mathrm{a}$ and $1 \mathrm{~b}$ in the Appendix.

\section{Procedure}

All the materials were presented on a computer screen using Google software. The entire task lasted about 15 minutes and participants were allowed to pace themselves. All the participants first answered a few socio-demographic questions and then proceeded to make their financial choices.

After choosing one option for all six financial products, the participants were asked which specific attribute in each option they considered more important. They could choose the first attribute, the second, or both attributes. It is important to note that we obtained the attribute importance ratings after the participants had chosen one of the two or three options, as asking about their preferred attribute in advance could have led them to make a different choice (Ariely \& Wallsten, 1995). We asked the following question about attribute importance (this example is for the first financial decision taskthe Loan): When evaluating the attributes of the loan, the attribute I consider more important is a) interest rate; b) processing fee; 
c) interest rate and processing fee are equally important to me.

Afterwards the participants were asked how familiar they were with each of the financial products on a three-point scale (Not familar; Partly familiar; Very familiar). We also measured how engaged they were with the financial product, asking them if they were willing to invest time and energy into seeking information when making a decision (Not willing to devote time and energy; Willing to devote reasonable time and energy; Willing to devote time and energy).

\section{Measuring the Attraction Effect}

The attraction effect was defined as the change in the proportion of participants choosing the two original options after the decoy had been introduced. To measure this change, in our study we compared the proportion of the participants choosing the target option and the competitor in the group without the decoy and in the groups where the decoy had been included in the set of options. Since the proportion choosing the decoy also rises (though minimally), the technique for calculating the effect varies depending on whether the proportion selecting the decoy is included. Based on a detailed description of computational techniques in Malaviya and Sivukumar's study (1998) and the most commonly used techniques (e.g., Lee et al., 2016; Malkoc et al., 2013; Pocheptsova et al., 2009), we decided to compute the difference in target choices when the decoy was absent and when it was present, without normalizing the target's share to account for the decoy share. Therefore, the participants who chose the decoy option were not included in the comparisons. The advantage of this procedure is that there is no need to adjust the proportion who selected the decoy, and the direct absolute measure of the effect can be obtained. Malaviya and Sivukumar (1998) used and compared the various measures of the at- traction effect and found that interpretations of the outcomes on the four measures were generally similar. The attraction effects were calculated separately for each product.

\section{Results}

For all the financial products, one third to two thirds of the participants considered the two attributes of the product to be equally important. Those participants who preferred one attribute over the other mostly agreed on which attribute they preferred in five of the six products. The attribute considered more important served as the target-attribute for our participants and was used in the attraction effect calculations. The subjective importance of the attributes (\%) is given in Table 2 in the Appendix.

To test our hypotheses, we compared the choices of participants who considered both attributes equally important with those of participants who considered the target-attribute more important. We calculated the manifestation of the attribution effect for the less important attribute as well; however, these results were either not significant or the number of participants was not suitable for analysis.

We produced descriptive results and performed a separate pairwise comparison analysis to show whether there was a statistically significant difference between the proportion choosing option A and the proportion choosing option $\mathrm{B}$ in the control group and in the two experimental groups. The results concerning whether the attraction effect could be seen in the participant choices according to whether there was preference for one attribute versus no preference are given separately for each product in Graphs 1a, 1b to 3a, 3b for the less familiar and Graphs 4a, 4b to 6a, 6b more familiar products.

As alreadymentioned, we decided to calculate the attraction effect as the difference in targetoption choices in the groups with the decoy and 

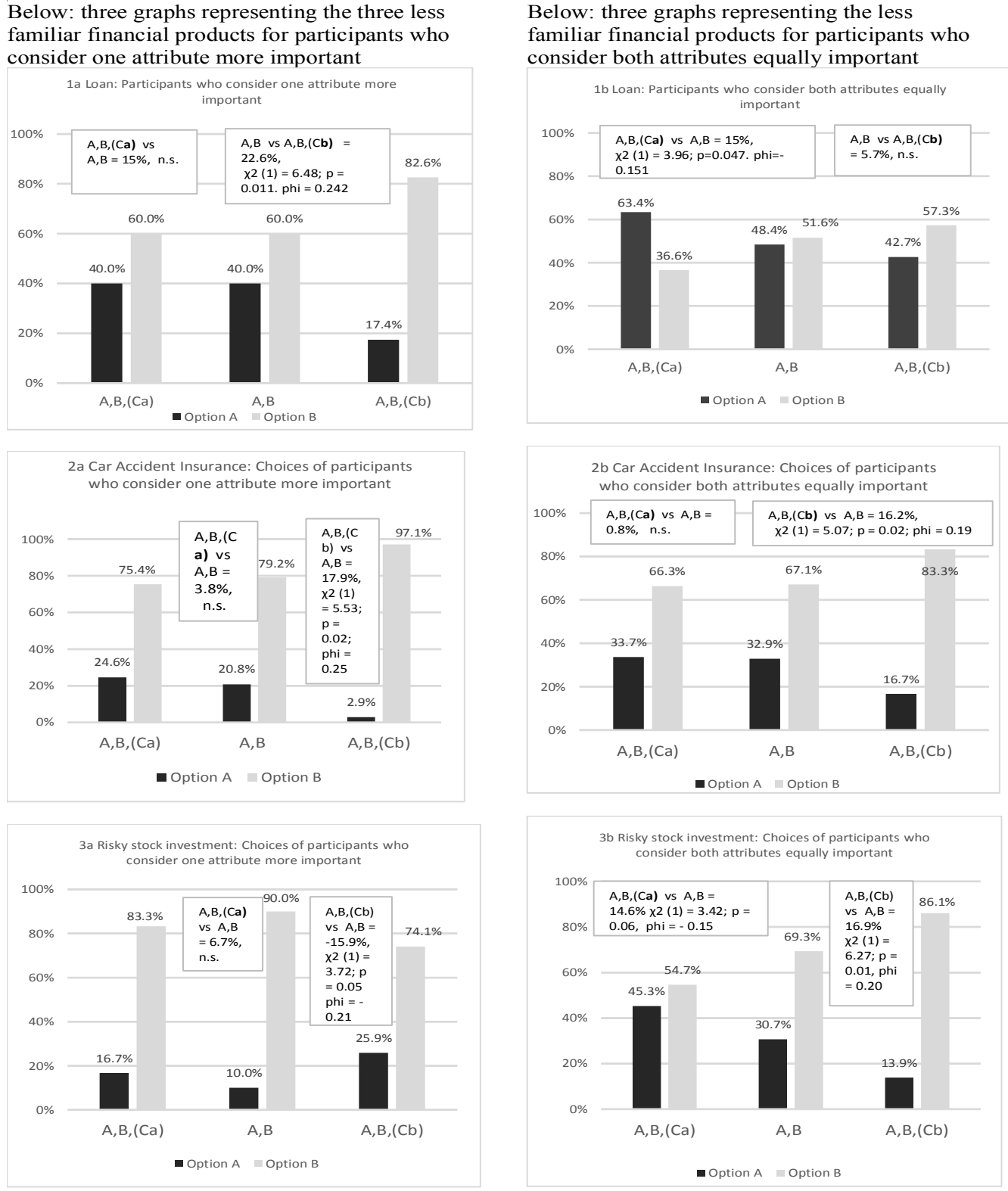

Graphs $1 a, 1 b, 2 a, 2 b, 3 a$, and $3 b$. The attraction effect in the participant choices according to whether there was preference for one attribute versus both attributes equally important for the less familiar products. 
Below: three graphs which represent three more familiar financial products for participants who consider one attribute more important
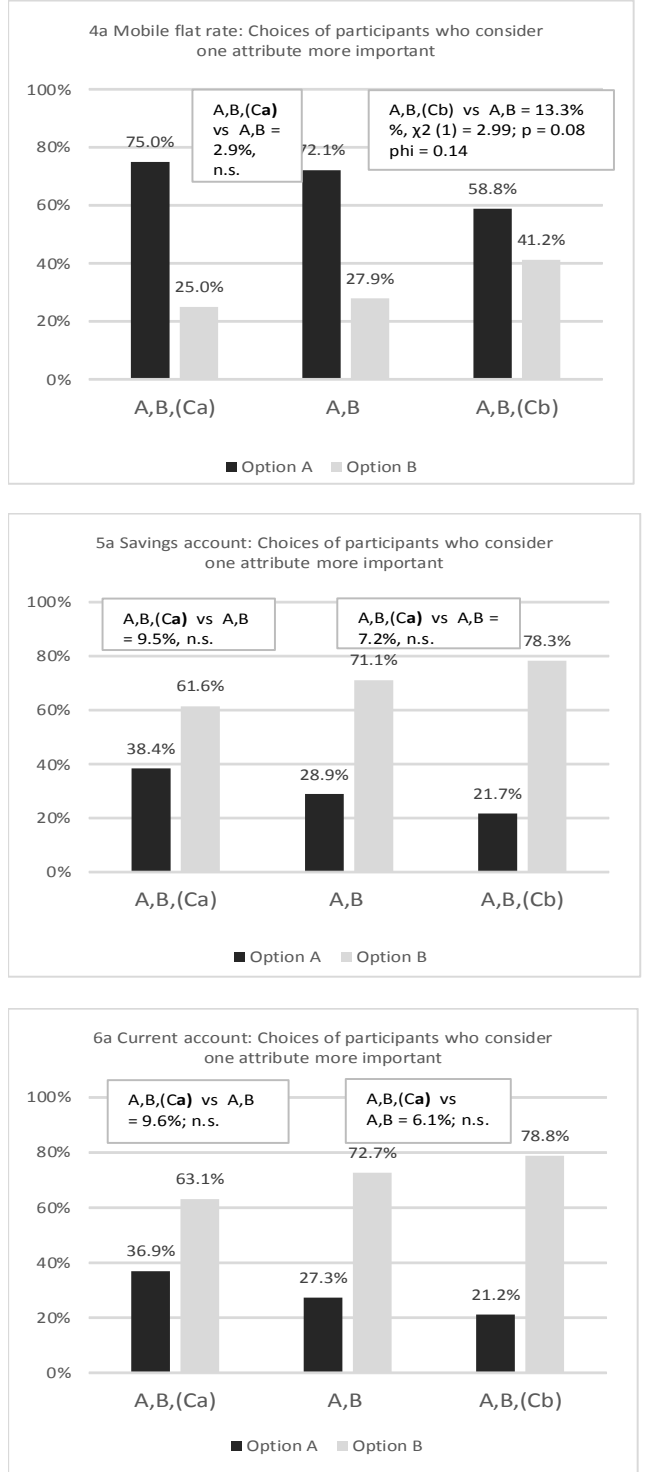

Below: three graphs which represent three more familiar financial products for participants who consider both attributes equally important
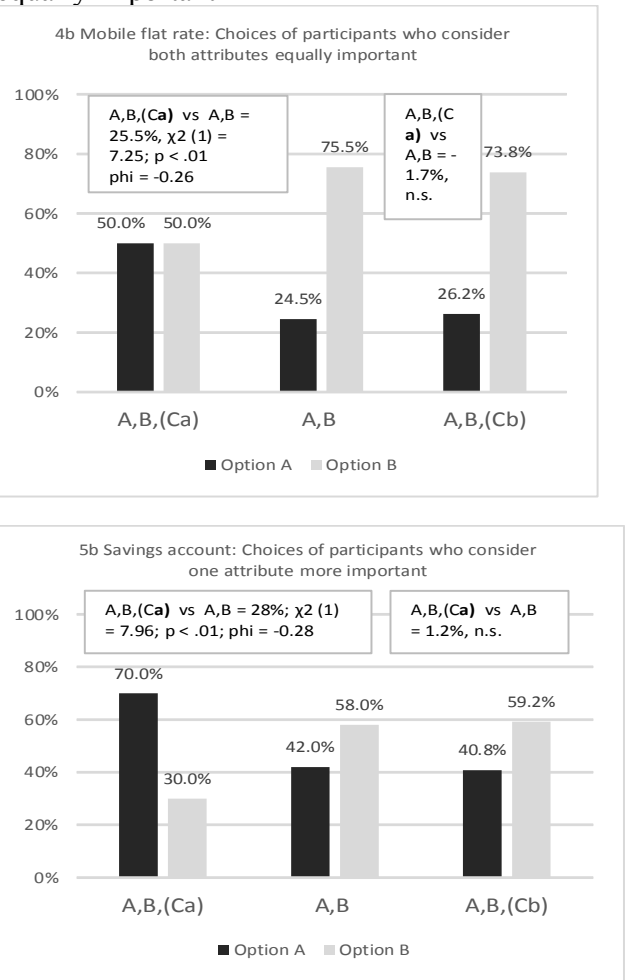

6b Current account: Choices of participants who consider one attribute more important

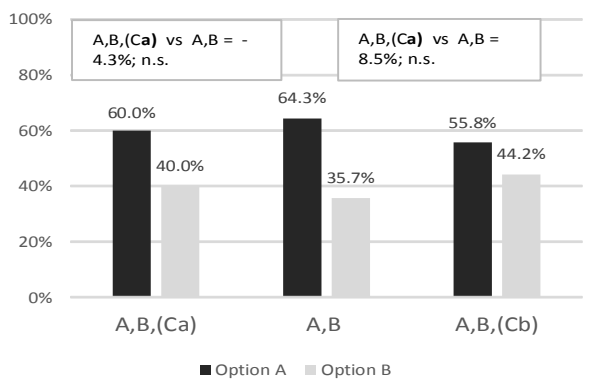

Graphs $3 a, 3 b, 4 a, 4 b, 5 a$, and $5 b$. The attraction effect in the participant choices according to whether there was preference for one attribute versus both attributes equally important for more familiar products. 
without the decoy, without normalizing the target share to account for the decoy share. Therefore, the participants who chose the decoy option were not included in the comparisons and are not shown in the results graphs ${ }^{1}$.

The Graphs 1a, $1 \mathrm{~b}$ to $6 \mathrm{a}, 6 \mathrm{~b}$ show the graphical representation and calculations of the control and experimental group choices and the attraction effect. Where the results were not significant, we have not reported the chi square or effect sizes, just the percentage value. Values close to significance are reported as well. A positive value means that the decoy was effective, but in most cases it was not significant. In all cases, the decoy led to an increase in the target-option being selected except in the case of Risky Stock Investment, where a repulsion effect was observed.

For the participants who considered both product attributes to be important, the attraction effect was observable in five of the six financial products. It was not observed in the Current Account product. For those participants who preferred one attribute, the attraction effect was observed in two of the six financial products. In both cases, the decoy increased the attractiveness of the option that did better on the attribute considered more important by the participants. Both of the products where the attraction effect was observed were less familiar and had long-term consequences (Loan and Car Accident Insurance).

As expected, the participants had a high degree of engagement with almost all the financial products. Above $87 \%$ reported a willing-

\footnotetext{
${ }^{1}$ The decoy was chosen by $5-11 \%$ of the participants; the smallest proportion selected the decoy in the Mobile Flat Rates task (4.4-5.9\% of participants) and the largest proportion selected the decoy in the Car Accident Insurance task (10-11\% of participants). These figures are similar to those obtained in most of the attribution effect studies (for example, Malaviya \& Sivakumar, 1998; Malkoc et al., 2013; Mishra et al., 1993; Simonson, 1989).
}

ness to spend time and energy choosing and purchasing each of the financial products. Good familiarity with the most frequently used financial products (Mobile Rate, Current Account, and Savings Account) was reported by 84-95\% of the participants. Participants reported being less familiar with the less frequently used financial products (Loan 76\%, Car Accident Insurance 56\%, and Investment $39 \%$ ). The product students were least familiar with was the Risky Stock Investment, with $61 \%$ of participants being unfamiliar with it. The exact data on participants' familiarity and engagement with the financial products is shown in Table 3 in the Appendix.

To test Hypothesis 3 we compared the choices of the less familiar and more familiar financial products with respect to whether the participants considered one or both attributes to be important. For the more familiar products (Mobile Rates, Current Accounts and Savings Accounts), the attraction effect was observed only in participants considering both attributes equally important. This applied to two of the three products (Mobile Rates and Savings Accounts). For those participants who considered one attribute to be important, the attraction effect did not appear in any of the three familiar products.

For the less familiar products (Loan, Car Accident Insurance, and Investment), the attraction effect was observed for all three products for participants preferring two attributes. For participants preferring one attribute, the attraction effect was observed in relation to two of the three products (Loan and Car Accident Insurance), for the third product (Investment), the attraction effect occurred in reverse, manifesting as the repulsion effect. Concerning Hypothesis 3 , the results showed that participants who considered two attributes to be equally important yielded more to the attraction effect in both familiar and less familiar products compared to those who prefered only one attribute. 


\section{Discussion}

In our study, we attempted to verify the assumption that the attraction effect occurs when a financial product is being selected under the condition of a preference for both or one of the attributes of the financial product. Unlike other studies in this field, our design included questions about the importance participants assigned to the attributes of each option. This allowed us not only to test whether the attraction effect occurred, but also whether it was present when participants considered the attributes of the options to be more or less or equally important. We also attempted to establish participants' familiarity and engagement with the financial products.

The main result of our study is that when people care more about one attribute than the other the attraction effect plays less of a role in financial product choices. The attraction effect was present more frequently in decision making when participants had no clear attribute preference. Those with a clear preference for one attribute succumbed to the effect only when choosing a product they were less familiar with (and which had serious potential consequences). We can consider our hypotheses to be supported. These results have brought new insights as the two moderators of the attraction effect (familiarity and attribute preference) have not been extensively studied so far.

The attraction effect occurs when people use the dominance relationship as a heuristic to avoid trade-offs between attributes (Hedgcock \& Rao, 2009), and our participants tended to do this in their financial choices. Our findings that the attraction effect was less likely to occur when participants had a preference for one attribute and more likely to occur when they considered both attributes important support Ariely and Wallsten's theory (1995) that the conflict inherent in choosing between options that differ in two similarly weighted attributes helps to create the conditions for context-dependent choices to occur. Our results also indicate that the greater subjective importance of one attribute reduces the attraction effect because the preference of one attribute over the other serves as a guide when choosing a financial product.

From one to two thirds of our participants considered both attributes of the financial products to be equally important. A similar proportion of participants considered one attribute more important. This can be labeled as the focal or critical attribute. It was a target-attribute for our participants, and we assume that it served as an important guide to them when thinking about which financial product to choose.

The financial task that was least familiar to our participants was the Risky Stock Investment. In participants' decision on this product, we identified a repulsion effect, which is the corollary to the attraction effect. The latter occurs when a third inferior option is added to a set of two non-dominating options. In this scenario the share of participants choosing the "dominating" option (referred to as "the target") increases. If the addition of the third inferior option increases the share of participants choosing the non-dominating option (referred to as "the competitor"), we refer to this as the repulsion effect (Simonson, 2014).

Where the Investment Stocks were concerned, those participants who considered the risk of making a loss (target-attribute) more important than the return, the addition of the decoy reducing the risk of loss led to an increase in the proportion choosing the option that did better on the return, which was the competitor. The decoy did not therefore have the intended effect, as it elicited the repulsion effect rather than the attraction effect. According to Simonson (2014), it is the nature of the relationship between the two adjacent options that moderates the resulting effect. We could interpret this phenomenon as entering loss aver- 
sion into the interaction between the decoy and the gain and risk attributes of the investment. According to the prospect theory (Tversky \& Kahneman, 1991), there are differences in sensitivity to gain and loss, and there are also individual differences in risk tolerance, and these were manifested in participants' preferences for the risk or gain attributes or both.

A practical implication of our findings is that expressing the attribute values numerically does not prevent biases in consumer decisions on financial products when the total values of the options are difficult to calculate. Another implication may be that if consumers have a clear preference for an attribute of a financial option, the attraction effect may be less strong than when there is no attribute preference.

Asymmetric dominance is not the only or even the main factor in any choice. There is no doubt that a choice of an option from the set of options is not determined only by set configuration. The driving forces behind product choices can be product type, the importance and nature of the attributes on which the options differ, the attribute values, decision maker characteristics, and various other factors (Simonson, 2014).

\section{Limitations}

There are several limitations of this study. First limitation of the research could be that the attraction effect was tested using university students, and they may be more familiar with some but not with all of the financial products. Students were less knowledgeable about some financial products, such as the Loan or Car Accident Insurance, but they were well informed about Mobile Rates and Current Accounts. Another limitation is that university students are better cognitively predisposed than the representative sample of the adult population for solving the tasks we used, therefore, our results could differ from the general adult popu- lation. Third possible limitation is that financial products are specific decision tasks, which are closely related to the country of origin and its financial background, financial culture, financial education, level of development, regulation and law and are not easily transferable to other countries without proper adjustment. Purely Slovak sample describes the situation in Slovakia, which could differ from countries.

\section{Conclusion}

The impact of attribute importance on the attraction effect remains unclear, especially with regards the financial domain. We consider our study to be a pilot study on attraction effect in the financial domain, which can provide a basis for further research. Our findings indicate that under certain conditions the attraction effect and repulsion effect can be observed in the financial domain as well. However, more specific and detailed research exploring the effect under combinations of conditions of familiarity versus engagement versus attribute importance is needed to determine how the attraction effect works. Our study may also provide inspiration to create a more elaborate model of the conditions in which one can expect the attraction effect to occur in the financial domain.

\section{References}

Ariely, D., \& Wallstein, T. S. (1995). Seeking subjective dominance in multidimensional space: An explanation of the asymmetric dominance effect. Organizational Behavior And Human Decision Processes, 63(3), 223-232. doi: 10.1006/obhd.1995. 1075

Dhar, R., \& Simonson, I. (2003). The effect of forced choice on choice. Journal of Marketing Research, 40(2), 146-160. doi: 10.1509/jmkr.40.2.146.19229

Frederick, S., Lee, L., \& Baskin, E. (2014). The limits of attraction. Journal of Marketing Research, 51(4), 487-507. doi: 10.1509/jmr.12.0061

Hedgcock, W., \& Rao, A. R. (2009). Trade-off aversion as an explanation for the attraction effect: A functional magnetic resonance imaging study. Jour- 
nal of Marketing Research, 46, 1-13. doi: 10.1509/ jmkr.46.1.1

Herne, K. (1999). The effects of decoy gambles on individual choice. Experimental Economics, 2, 3140. doi: 10.1023/A:1009925731240

Huber, J., Payne, J. W., \& Puto, C. P. (1982). Adding asymmetrically dominated alternatives: Violations of regularity and the similarity hypothesis. The Jour nal of Consumer Research, 9(1), 90-98. doi $10.1086 / 208899$

Huber, J., Payne, J. W., \& Puto, C. P. (2014). Let's be honest about the attraction effect. Journal of Marketing Research, 51(4), 520-525. doi: 10.1509/ jmr. 14.0208

Lee, C. F., Chuang S. C., Chiu, C. K., \& Lan, K. H. (2016). The influence of task difficulty on context effect - compromise and attraction effects. Current Psychology, 1-18. Retrieved from: http://link. springer.com/article/1 0.1007\%2Fs $12144-016$ 9428-0. doi: 10.1007/s12144-016-9428-0

Lichters, M., Sarstedt, M., \& Vogt, B. (2015). On the practical relevance of the attraction effect: A cautionary note and guidelines for context effect experiments. Academy of Marketing Science Review, 5(1), 1-19. doi: 10.1007/s13162-015-0066-8

Malaviya, P., \& Sivakumar, K. (1998). The moderating effect of product category knowledge and attribute importance on the attraction effect. Marketing Letters, 9(1), 93-106. doi: 10.1023/A: 1007976305757

Malkoc, S. A., Hedgcock, W., \& Hoeffler, S. (2013). Between a rock and a hard place: The failure of the attraction effect among unattractive alternatives. Journal of Consumer Psychology, 23(3), 317-329. doi: $10.1016 /$ j.jcps.2012.10.008

Mishra, S., Umesh, U. N., \& Stem, D. E. (1993). Antecedents of the attraction effect: An informationprocessing approach. Journal of Marketing Research, 30, 331-349. doi: 10.1177/002224379303000305

Payne, J. W., Bettman, J. R., \& Johnson, E. J. (1993) The adaptive decision maker. Cambridge University Press. doi: 10.1017/CBO9781139173933

Pocheptsova, A., Amir, O., Dhar, R., \& Baumeister, R. F. (2009). Deciding without resources: Resource depletion and choice in context. Journal of Marketing Research, 46(3), 344-355. doi: 10.1509/ jmkr.46.3.344

Simonson, I. (1989). Choice based on reasons: The case of attraction and compromise effects. Journal of Consumer Research, 16, 158-74. doi: 10.1086/ 209205

Schwarzkopf, D. L. (2003). The effects of attraction on investment decisions. The Journal of Behavioral Finance, 4(2), 96-108. doi: 10.1207/ S15427579JPFM0402_06

Simonson, I. (2014). Vices and virtues of misguided replications: The case of asymmetric dominance. Journal of Marketing Research, 51(4), 514-519. doi: 10.1509/jmr.14.0093

Simonson, I., \& Tversky, A. (1992). Choice in context: Tradeoff contrast and extremeness aversion. Journal of Marketing Research, 29(3), 281-295. doi: $10.1177 / 002224379202900301$

Sivakumar, K., \& Cherian, J. (1995). Role of product entry and exit on the attraction effect. Marketing Letters, 6(1), 45-51. doi: 10.1007/BF00994039

Tversky, A., \& Kahneman, D. (1991). Loss aversion in riskless choice: A reference-dependent model. The Quarterly Journal of Economics, 106(4), 10391061. doi: 10.2307/2937956

Tversky, A., \& Simonson, I. (1993). Contextdependent preferences. Management Science, 39(10), 1179-1189. doi: 10.1287/mnsc.39.10. 1179

Wedell, D. H., \& Pettibone, J. C. (1996). Using judgments to understand decoy effects in choice. Organizational Behavior and Human Decision Processes, 67(3), 326-344. doi: 10.1006/obhd. 1996.0083

Yang, S., \& Lynn, M. (2014). More evidence challenging the robustness and usefulness of the attraction effect. Journal of Marketing Research, 51(4), 508513. doi: $10.1509 /$ jmr. 14.0020

Zhumakadyr uulu, K., \& Koenig, N. (2014). The role of context effect in the choice of financial products: An experimental investigation in the Kyrgyz Republic. Central Asia Business Journal, 6(1), 520 . 


\section{Appendix}

\section{Figures}

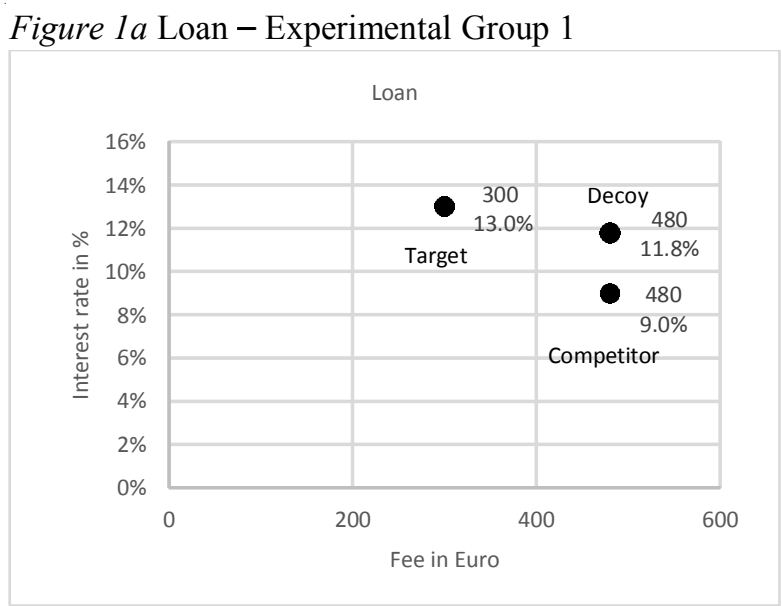

Figure $1 b$ Loan - Experimental Group 2

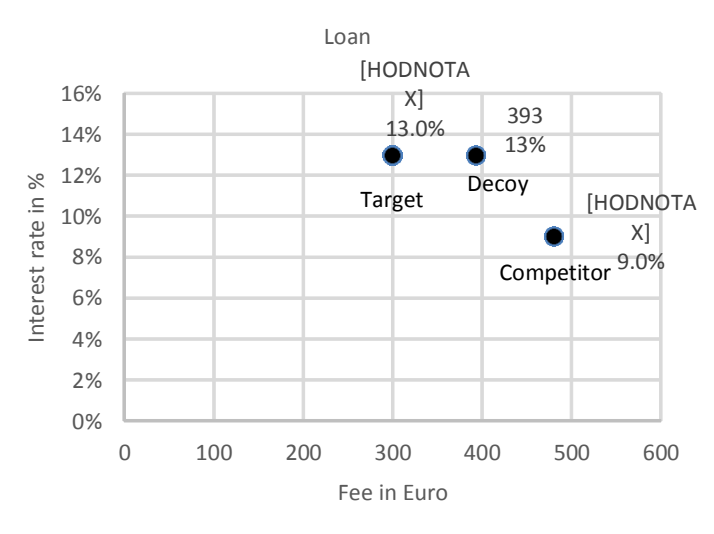

Figure 1a, 1b. Example decoys created for the Loan financial product for both experimental groups 


\section{Tables}

Table 1 Descriptions of financial products and attribute values used in the decision tasks

\begin{tabular}{lccccc}
\hline PRODUCT & Attribute 1 & Attribute 2 & PRODUCT & Attribute 1 & Attribute 2 \\
\hline Loan & $\begin{array}{c}\text { Interest rate } \\
(\%)\end{array}$ & Processing fee $(€)$ & $\begin{array}{c}\text { Car accident } \\
\text { insurance }\end{array}$ & $\begin{array}{c}\text { Yearly } \\
\text { insurance } \\
\text { payment }(€)\end{array}$ & $\begin{array}{c}\text { Accident } \\
\text { repair fee }(€)\end{array}$ \\
Option A & $13 \%$ & $€ 300$ & Option A & $€ 250$ & $€ 180$ \\
Option B & $9 \%$ & $€ 480$ & Option B & $€ 130$ & $€ 300$ \\
Decoy Ca & $13 \%$ & $€ 393$ & Decoy Ca & $€ 250$ & $€ 235$ \\
Decoy Cb & $11.80 \%$ & $€ 480$ & Decoy Cb & $€ 170$ & $€ 300$ \\
\hline Risky stock & Estimated & Probability of & Mobile flat rate & Monthly fee & Discount on \\
investment & yield $(\%)$ & losing all money & & $(€)$ & new mobile \\
& & invested $(\%)$ & & & phone $(€)$ \\
Option A & $37 \%$ & $10 \%$ & Option A & 15 & $€ 20$ \\
Option B & $30 \%$ & $5 \%$ & Option B & 19 & $€ 110$ \\
Decoy Ca & $34 \%$ & $10 \%$ & Decoy Ca & 17 & $€ 20$ \\
Decoy Cb & $30 \%$ & $5.40 \%$ & Decoy Cb & 19 & $€ 96$ \\
\hline Savings account & Annual & Early withdrawal & Current & Account & Reward for \\
& interest rate & fee $(\%)$ & account & maintenance & each card \\
& $(\%)$ & & & fee $(€)$ & payment (\%) \\
Option A & $0.90 \%$ & $4 \%$ & Option A & $€ 1.90$ & $0.60 \%$ \\
Option B & $1.25 \%$ & $8 \%$ & Option B & $€ 1$ & $0.30 \%$ \\
Decoy Ca & $0.90 \%$ & $4.60 \%$ & Decoy Ca & $€ 1.90$ & $0.42 \%$ \\
Decoy Cb & $1.07 \%$ & $8 \%$ & Decoy Cb & $€ 1.30$ & $0.30 \%$ \\
\hline
\end{tabular}

Table 2 Subjective importance of the attributes (\%)

\begin{tabular}{|c|c|c|c|}
\hline Financial product & $\begin{array}{l}\text { Participants preferring } \\
\text { Attribute } 1\end{array}$ & $\begin{array}{l}\text { Participants preferring } \\
\text { Attribute } 2\end{array}$ & $\begin{array}{l}\text { Participants } \\
\text { preferring both } \\
\text { attributes equally }\end{array}$ \\
\hline Loan & $\mathbf{4 0 . 2 \%}$ Interest rate & $4.9 \%$ Processing fee & $54.8 \%$ \\
\hline $\begin{array}{l}\text { Car accident } \\
\text { insurance }\end{array}$ & $\begin{array}{l}\text { 32.2\% Yearly insurance } \\
\text { payment }\end{array}$ & $16.8 \%$ Accident repair fee & $50.9 \%$ \\
\hline $\begin{array}{l}\text { Risky stock } \\
\text { investment }\end{array}$ & $19.3 \%$ Estimated yield & $\begin{array}{l}\text { 31.4\% Probability of losing } \\
\text { all money invested }\end{array}$ & $49.3 \%$ \\
\hline Mobile flat rate & $52.8 \%$ Monthly fee & $\begin{array}{l}16 \% \text { Discount on new mobile } \\
\text { phone }\end{array}$ & $31.2 \%$ \\
\hline Savings account & $\mathbf{5 5 \%}$ Annual interest rate & $11.3 \%$ Early withdrawal fee & $33.7 \%$ \\
\hline Current account & $\begin{array}{l}\text { 39.8\% Account } \\
\text { maintenance fee }\end{array}$ & $\begin{array}{l}19.1 \% \text { Reward for each card } \\
\text { payment }\end{array}$ & $41.1 \%$ \\
\hline
\end{tabular}


Table 3 Participants' familiarity and engagement with the financial products

\begin{tabular}{lrccccc}
\hline \multirow{2}{*}{ Financial product } & \multicolumn{3}{c}{ Familiarity (\%) } & \multicolumn{3}{c}{ Engagement (\%) } \\
\cline { 2 - 7 } & $\begin{array}{c}\text { Not } \\
\text { familiar }\end{array}$ & $\begin{array}{c}\text { Partly } \\
\text { familiar }\end{array}$ & $\begin{array}{c}\text { Very } \\
\text { familiar }\end{array}$ & $\begin{array}{c}\text { Not willing } \\
\text { to devote } \\
\text { time and } \\
\text { energy }\end{array}$ & $\begin{array}{c}\text { Willing to } \\
\text { devote } \\
\text { reasonable } \\
\text { time and } \\
\text { energy }\end{array}$ & $\begin{array}{c}\text { Willing } \\
\text { to devote } \\
\text { time and } \\
\text { energy }\end{array}$ \\
\hline Loan & 24.4 & 65.5 & 10.1 & 6.4 & 32.6 & 61.0 \\
Car accident insurance & 44.4 & 45.6 & 10.0 & 8.6 & 36.8 & 54.6 \\
Risky stock investment & 61.0 & 31.2 & 7.8 & 12.9 & 37.8 & 49.3 \\
Mobile flat rate & 4.5 & 43.1 & 52.4 & 5.8 & 39.6 & 54.6 \\
Savings account & 15.6 & 57.7 & 26.7 & 5.5 & 38.4 & 56.1 \\
Current account & 5.3 & 49.5 & 45.2 & 3.5 & 38.4 & 58.1 \\
\hline
\end{tabular}

